Revista Arbitrada Interdisciplinaria KOINONIA

Año V. Vol V. N9. Enero - Junio 2020

Hecho el depósito de Ley: FA2016000010

ISSN: 2542-3088

FUNDACIÓN KOINONIA (F.K). Santa Ana de Coro. Venezuela.

Jhonny Marcelo Orozco-Ramos; Juan Carlos Cayán-Martínez; Eduardo Francisco García-Cabezas; Gabriel Pilataxi-Contreras

http://dx.doi.org/10.35381/r.k.v5i9.677

\title{
Implementación de un sistema de recolección y cloración para la potabilización automatizada
}

\section{Implementation of a collection and chlorination system for automated purification}

\author{
Jhonny Marcelo Orozco-Ramos \\ hhonny.orozco@espoch.edu.ec \\ Escuela Superior Politécnica de Chimborazo, Riobamba \\ Ecuador \\ https://orcid.org/0000-0003-2016-0426 \\ Juan Carlos Cayán-Martínez \\ jcayan@espoch.edu.ec \\ Escuela Superior Politécnica de Chimborazo, Riobamba \\ Ecuador \\ https://orcid.org/0000-0001-9573-3706 \\ Eduardo Francisco García-Cabezas \\ edugarciac87@hotmail.com \\ Escuela Superior Politécnica de Chimborazo, Riobamba \\ Ecuador \\ https://orcid.org/0000-0002-3547-472X \\ Gabriel Pilataxi-Contreras \\ gabrielpilataxi@hotmail.com \\ Escuela Superior Politécnica de Chimborazo, Riobamba \\ Ecuador \\ https://orcid.org/0000-0002-5644-8299
}

Recibido: 20 de febrero de 2020

Revisado: 17 de marzo de 2020

Aprobado: 03 de abril de 2020

Publicado: 29 de abril de 2020 


\section{RESUMEN}

La investigación se planteó como objetivo general diseñar e implementar un sistema de recolección y cloración para la potabilización automatizada en Mollepamba, AmbatoTungurahua. Se trabajó mediante el método de clorado. El sistema de clorado debe ajustarse a las necesidades requeridas por parte de los habitantes por lo cual se plantearon tres sistemas considerando para el caserío los aspectos más representativos para la selección como costo, modo de funcionamiento, número de habitantes, según los sistemas existentes en el mercado. Al ser un sistema desarrollado para el consumo humano se realizó pruebas de funcionabilidad de todos los elementos, sometiéndolo a pruebas de campo antes de su instalación final, para asegurar su correcto funcionamiento se montó los elementos en placas de baquelita fenólica. Una vez cubiertas las pruebas de campo se procedió a su instalación final.

Descriptores: Agua potable; tratamiento del agua; servicio de utilidad pública; automatización. (Palabras tomadas de Tesauro UNESCO).

\section{ABSTRACT}

The general objective was to design and implement a collection and chlorination system for automated purification in Mollepamba, Ambato - Tungurahua. It was worked by the chlorination method. The chlorination system must adjust to the needs required by the inhabitants, for which reason three systems were proposed, considering for the village the most representative aspects for selection such as cost, mode of operation, number of inhabitants, according to the existing systems in the market. Being a system developed for human consumption, functionality tests were carried out on all the elements, subjecting them to field tests before their final installation, to ensure their correct operation, the elements were mounted on phenolic bakelite plates. Once the field tests were covered, the final installation was carried out.

Descriptors: Drinking wáter; water treatment; public utilities; automation. (Words taken from UNESCO Thesaurus).

\section{INTRODUCCIÓN}

En el Ecuador, los problemas que se presentan generalmente en los sistemas de suministro de agua potable son: (i) bajos niveles de cobertura, especialmente en áreas rurales; (ii) pobre calidad y eficiencia del servicio; y (iii) una limitada recuperación de costos y un alto nivel de dependencia en las transferencias financieras de los gobiernos nacionales y sub nacionales. Siendo necesario contar con un adecuado suministro de 
agua potable para la población (Guillemes Peira, 2015), con la finalidad de garantizar calidad de vida, la Revista ARQHYS (2012), explica que:

El sistema de suministro de agua potable es un procedimiento de obras de ingeniería, que con un conjunto de tuberías enlazadas nos permite llevar el agua potable hasta los hogares de las personas de una ciudad, municipio o área rural comparativamente tupida (p. 1).

Siendo pertinente diseñar sistemas automatizados que permitan proyectar desde la ingeniería, soluciones a la población, especialmente a las más vulnerables desde el índole socioeconómico, por lo tanto, el agua como derecho universal de la humanidad, debe ser provista en la mejor condición posible, siendo necesaria la calidad de potabilización de la misma (Briñez, Guarnizo \& Arias, 2012), sin embargo, tiende a ocurrir que en el Ecuador, no se genera en todos sus espacios geográficos, el servicio de potabilidad en alta optimización para el consumo humano. Una evidencia de esta problemática es el sistema de suministro de agua potable del caserío Mollepamba parroquia Picaihua del cantón Ambato provincia de Tungurahua (Cárdenas, \& Patiño, 2011).

El problema del sistema de suministro de agua potable del caserío Mollepamba es la falta de control de la dosificación del cloro en el proceso de desinfección del agua, por lo cual se suministra a la población una pobre calidad de agua (Pérez-Vidal, Díaz-Gómez, Salamanca-Rojas \& Rojas Torres, 2016). La utilización y consumo de agua de mala calidad produce enfermedades como: cólera, tifoidea, amebiasis, hepatitis y diarreas (Molina, Quesada, Calle, Ortiz \& Orellana, 2018). Por lo cual es necesario que los sistemas de suministro de agua potable proporcionen un líquido vital de alta calidad. HIDRITEC (2016), indica que:

En los sistemas de suministro de agua potable, la cloración es una opción de tratamiento de bajo costo que se utiliza para mejorar el sabor y la claridad del agua a la vez que se eliminan muchos microorganismos como bacterias y virus (p. 1).

Por lo tanto, se genera un problema multidisciplinar a causa del escaso tratamiento en la potabilización del agua Mercado Dávila, Márquez Rosano, Noriero Escalante \& Cervantes 
Herrera, 2019), sin embargo, la actual investigación se aborda desde la ingeniería, aportando a la solución de una problemática, mediante la realización de un proyecto técnico en beneficio de optimizar la calidad del agua con fines de consumo humano, planteándose un sistema de clorado y monitoreo de niveles agua, cloro y oxígeno del agua potable del caserío Mollepamba" donde se pretende proporcionar un adecuado control y monitoreo al momento de la dosificación del cloro durante todo el proceso de desinfección, garantizando de esta manera un suministro de agua potable de alta calidad. Desde lo abordado, se tuvo por objetivo general diseñar e implementar un sistema de recolección y cloración para la potabilización automatizada en Mollepamba.

\section{MATERIAL Y MÉTODOS}

Para iniciar con la implementación se realizó un diseño base del sistema de cloración como se muestra en la figura1, el cual va desde el tanque de captación hacia el tanque de almacenamiento donde se realiza el clorado el mismo que será monitoreado, una vez aplicada la dosificación de cloro el agua se bombeará al tanque de distribución y finalmente a los domicilios.

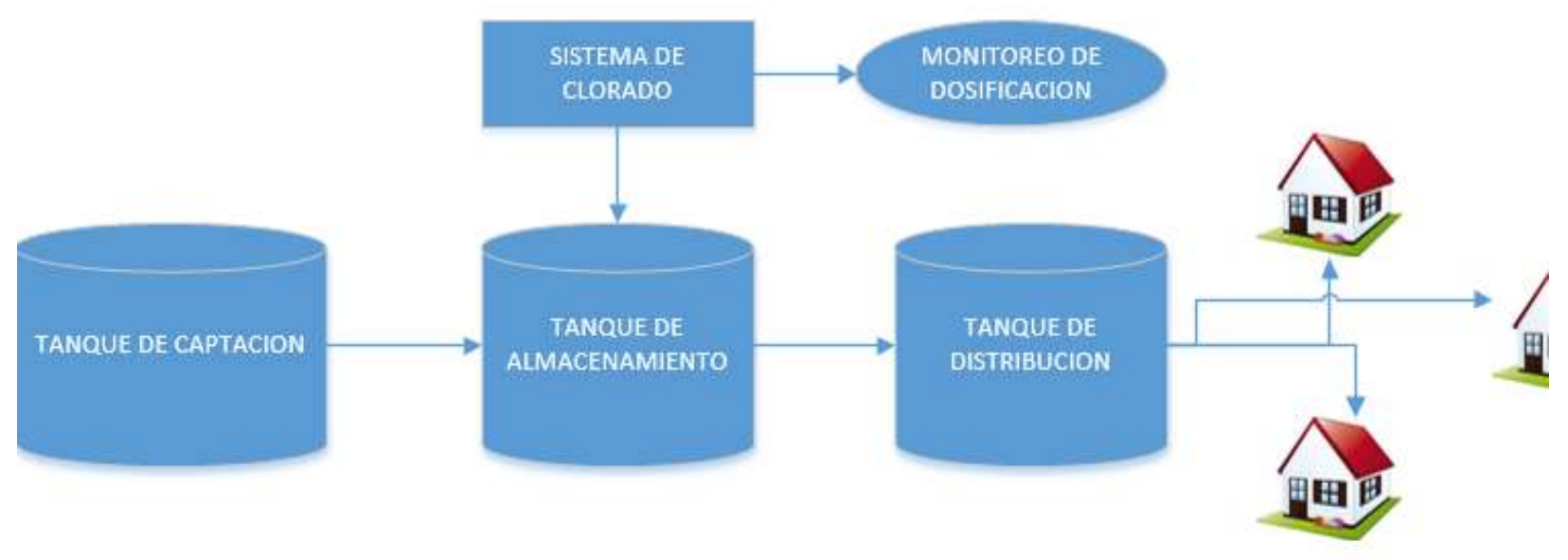

Figura 1. Diseño base del sistema de cloración. Elaboración propia. 
Revista Arbitrada Interdisciplinaria KOINONIA

Año V. Vol V. N 9 . Enero - Junio 2020

Hecho el depósito de Ley: FA2016000010

ISSN: 2542-3088

FUNDACIÓN KOINONIA (F.K). Santa Ana de Coro. Venezuela.

Jhonny Marcelo Orozco-Ramos; Juan Carlos Cayán-Martínez; Eduardo Francisco García-Cabezas; Gabriel Pilataxi-Contreras

\section{Sistema de clorado}

El sistema de clorado debe ajustarse a las necesidades requeridas por parte de los habitantes por lo cual se plantearon tres sistemas considerando para el caserío los aspectos más representativos para la selección como costo, modo de funcionamiento, número de habitantes, según los sistemas existentes en el mercado como:

\section{Cloro gaseoso}

1. Costo, Instalación costosa inalcanzable para comunidades pequeñas.

2. Modo de funcionamiento, Ofrece una alta precisión en la dosificación.

3. N de habitantes, $>5000$ a grandes ciudades.

\section{Cloro en solución}

1. Costo, costo intermedio a elevado para comunidades pequeñas.

2. Modo de funcionamiento, Puede introducirse la solución directamente en la tubería.

3. N de habitantes, $<5000$

\section{Cloro solido}

1. Costo, Costo intermedio ideal para comunidades pequeñas

2. Modo de funcionamiento, Una de las mejores soluciones para dosificación en la entrada de un tanque

3. N de habitantes, $<4000$

Con las características de los tres sistemas se selecciona el sistema de cloración sólida como se muestra en la Figura 2, debido a que el caserío cuenta con un número reducido de habitantes, este sistema es el más indicado en lugares rurales por su costo y facilidad de mantenimiento. Funcionan bajo el principio de carga constante con un dosificador de erosión que disuelve gradualmente las pastillas de hipoclorito de calcio, permitiendo dosificar hasta un caudal de 125ml/s para una concentración de cloro de 0.5 \% (5000 $\mathrm{mg} / \mathrm{l})$. Este sistema es el más recomendado en lugares rurales con un número menor a 4000 habitantes. 


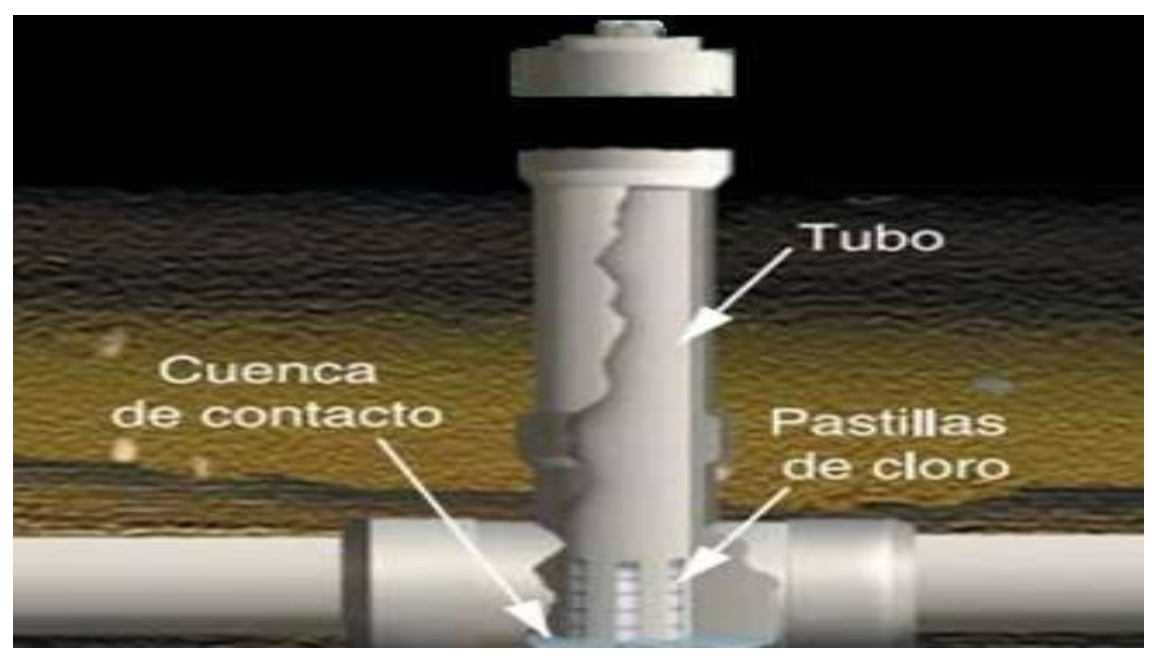

Figura 2. Sistema de cloración sólida. Fuente. HIDRITEC, 2016

Se prosigue con la selección del dosificador para identificar los accesorios que son incluidos y analizados la metodología de su funcionamiento, para su automatización y monitoreo. Se seleccionó un dosificador Accu-tab por sus dimensiones y tipo de material, las características e imagen se aprecian en la Figura 3. (HIDRITEC, 2016).

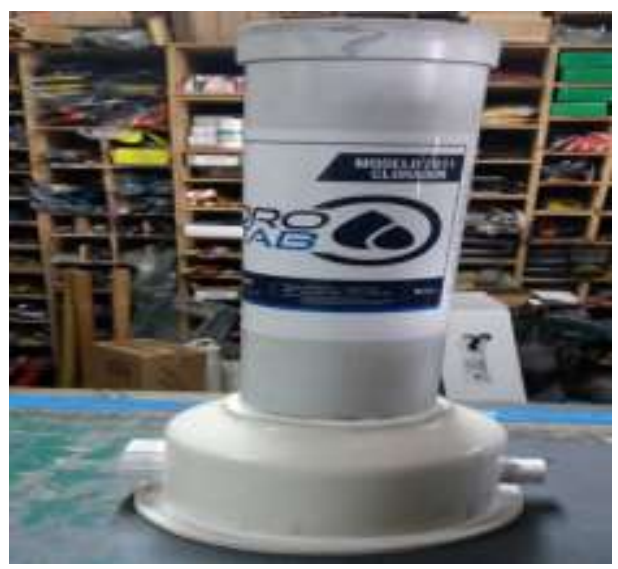

Figura 3. Dosificador Accu-tab. Fuente. HIDRITEC, 2016 
Revista Arbitrada Interdisciplinaria KOINONIA

Año V. Vol V. N 9 . Enero - Junio 2020

Hecho el depósito de Ley: FA2016000010

ISSN: 2542-3088

FUNDACIÓN KOINONIA (F.K). Santa Ana de Coro. Venezuela.

Jhonny Marcelo Orozco-Ramos; Juan Carlos Cayán-Martínez; Eduardo Francisco García-Cabezas; Gabriel Pilataxi-Contreras

\section{Tabla 1}

Caracteristicas del dosificador

\section{Características}

Dosificador de pastillas de hasta $10 \mathrm{KG}$

Soporta caudales de hasta $0.35 \mathrm{Its} / \mathrm{seg}$

Fabricado en ABS

Conexión de $20 \mathrm{~mm}$ de diámetro

Mínimo mantenimiento

Accesorios del dosificador de pastillas Accu-tab

Dosificador de pastillas Accu-tab

Tubería 3/4" (codos, uniones)

Válvula de globo

Fuente: HIDRITEC, 2016

El sistema de cloración que se implementa en el caserío Mollapamba funciona bajo el sistema de erosión, un dosificador será el encargado de disolver gradualmente pastillas de hipoclorito de calcio de alta concentración al hacer fluir una corriente de agua a través de las capsulas, el agua bajará desde un tanque elevado de 200 litros hacia el dosificador para mantener un flujo constante de agua según las pastillas se vayan diluyendo es necesario que se realice el cambio por otras nuevas.

Mientras las pastillas se vayan diluyendo la solución de cloro concentrada caerá por gravedad hacia el tanque reservorio en las concentraciones necesarias, en la parte final el agua del reservorio será impulsada mediante una bomba hacia un tanque que se encuentra en un lugar con gran elevación de donde el agua será distribuida a las casas de los habitantes del caserío. El sistema monitorea su funcionamiento inalámbricamente, con la visualización de datos como: nivel de cloro, cantidad de agua existente en el tanque de almacenamiento.

Al momento de trabajar con pastillas que se diluyen también se realiza un monitoreo del mismo es precisamente en este proceso donde se colocan sensores que medirán el nivel 
de las pastillas dentro del dosificador, cuando se presente un nivel crítico (nivel mínimo) el sistema enviará una señal de alarma mediante llamada al teléfono móvil del encargado de monitorear el sistema con ayuda de un Arduino y una red GPRS.

\section{Medidor de volumen de agua.}

El volumen de agua existente en el tanque de almacenamiento se mide por medio un sensor ultrasónico (Pérez de Diego, 2015). El funcionamiento del sensor ultrasónico es medir la distancia entre él y el objeto en este caso el agua, pero el valor que refleja sería el espacio libre como se ve en la Figura 4, es por eso que se aplicara una fórmula:

$$
y=\frac{(2 m-x) * 18000 l t}{2 m}
$$

Donde:

$y=$ volumen de agua existente

$\mathrm{X}=$ distancia medida por el sensor

$2 \mathrm{~m}=$ altura máxima del tanque y donde se posicionará el sensor

$18000 \mathrm{lt}=$ capacidad total del tanque

Con dicha fórmula se procede al cálculo del volumen existente en el tanque de almacenamiento.

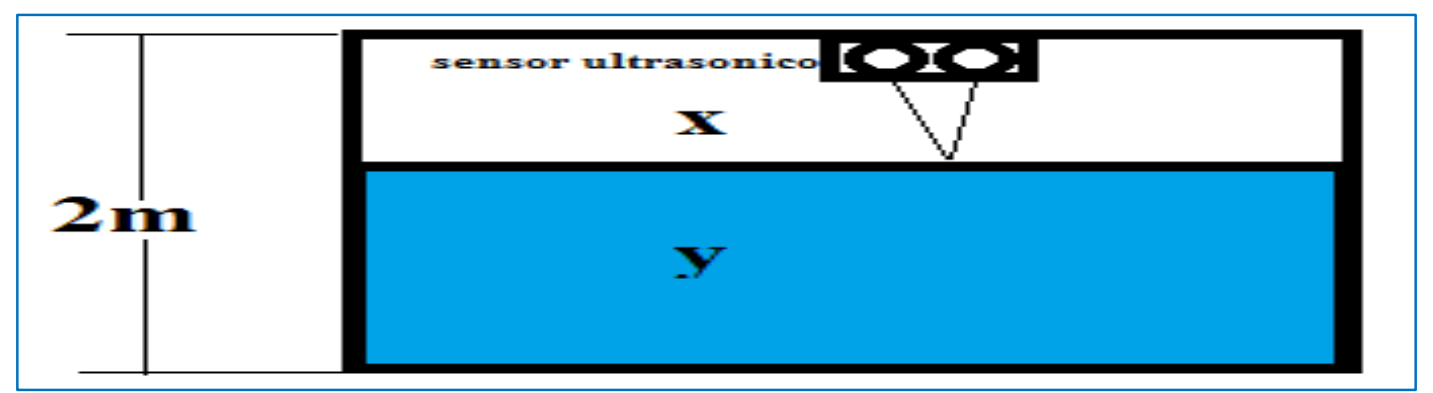

Figura 4. Posición del sensor para el cálculo de volumen. Fuente. Pérez de Diego, 2015. Instalación del servomotor para apertura de válvula de dosificación. 
Para la apertura gradual de la válvula de globo se realiza un acople entre la válvula y un servomotor como se observa en la Figura 5.

El principio de funcionamiento es de abrir o cerrar gradualmente dicha válvula comandado por los datos recibidos del sensor de nivel según el volumen de agua existente en el tanque de almacenamiento y controlar el flujometro, el mismo que controla la cantidad de cloro que cae al tanque desde 1,2 a 3,2 lpm, para lograr obtener una concentración de cloro 1mg/l según la norma INEN 1108 (Instituto Ecuatoriano de Normalización, 2011).

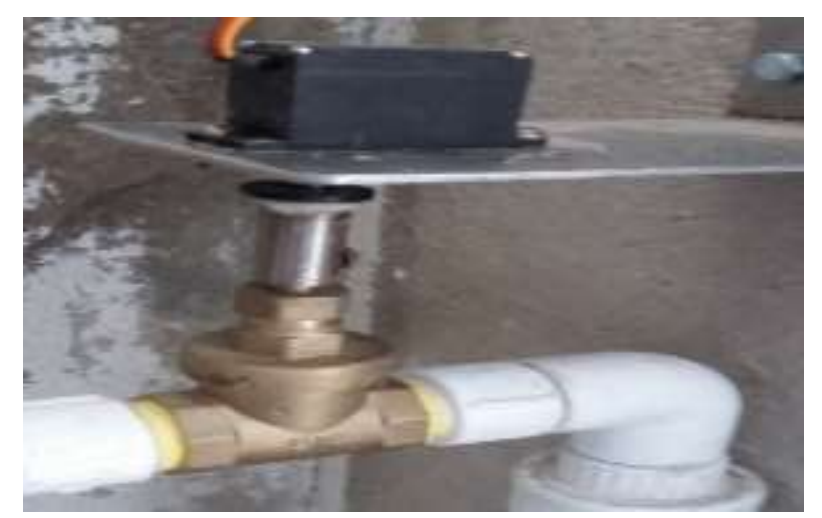

Figura 5. Instalación del acople y montaje del sistema.

Fuente. Pérez de Diego, 2015.

Para el proceso de datos se debe considerar el cálculo anterior de cantidad de volumen en el tanque de almacenamiento y transformarlos en datos reconocibles para el Arduino, con dichos datos se procede a comandar al servomotor con grados de giro el cual trasforma a un movimiento físico en la válvula.

Si se presenta la situación de no tener agua en dicho tanque el servomotor cerrará totalmente la válvula. Tomando en cuenta dichos datos y parámetros se realiza una programación para cumplir el propósito de automatización, dicha programación fue sometida a pruebas de funcionamiento. 


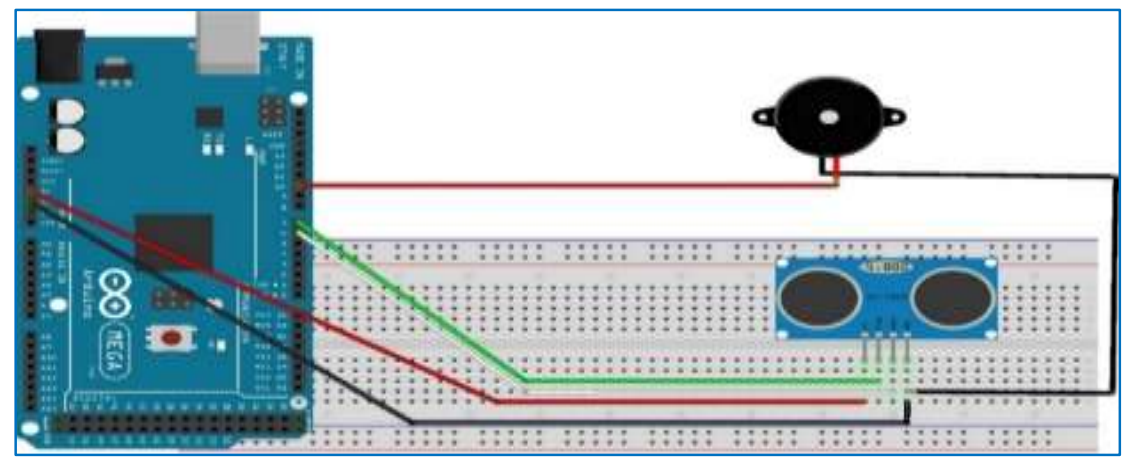

Figura 6. Diagrama de conexión. Fuente. Pérez de Diego, 2015.

La instalación del sistema medidor de pastillas de cloro es esencial para conocer la cantidad de pastillas que se encuentran para dosificar. Por la naturaleza del clorador se diseña un sistema para identificar la cantidad de pastillas existentes por medio de un clon de pastilla, es decir una pastilla falsa en la cual contendrá elementos magnéticos para su detección.

Al irse diluyendo las pastillas la pastilla falsa ira descendiendo y a la vez activando los sensores que indican el nivel en el que se encuentran junto al Arduino procesará la señal y dará como resultado si se encuentra en el 50\% (foco verde), 25\%(foco azul) o 10\%( foco rojo) como se ve en la Figura 7 , el cual es un nivel crítico y se debe recargar.

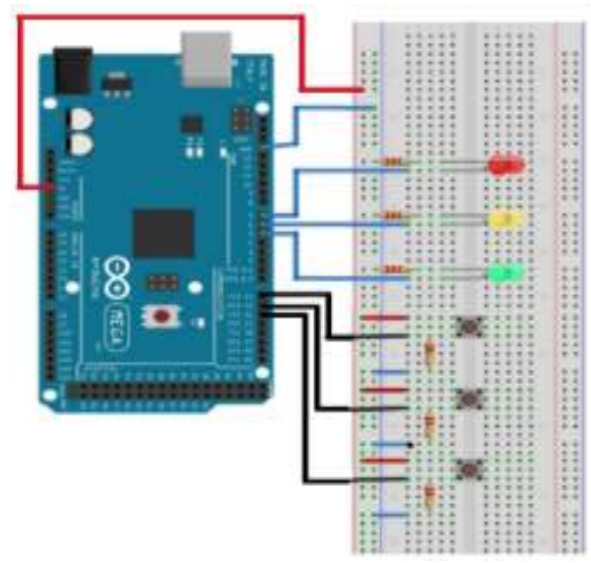

Figura 7. Diagrama de instalación. Fuente. Pérez de Diego, 2015. 
El momento en el cual el último sensor indica el $10 \%$ de nivel de pastillas de cloro se activa y procede a realizar una llamada de alerta durante 60 segundos la cual está configurado el número celular de la persona encargada. En el sistema de control del nivel de pastillas en el dosificador se adiciona el shield SIM 900 el cual ayuda a cumplir la meta propuesta que es la alerta de llamada para su posterior recarga de pastillas de hipoclorito de calcio como se muestra en la Figura 8.

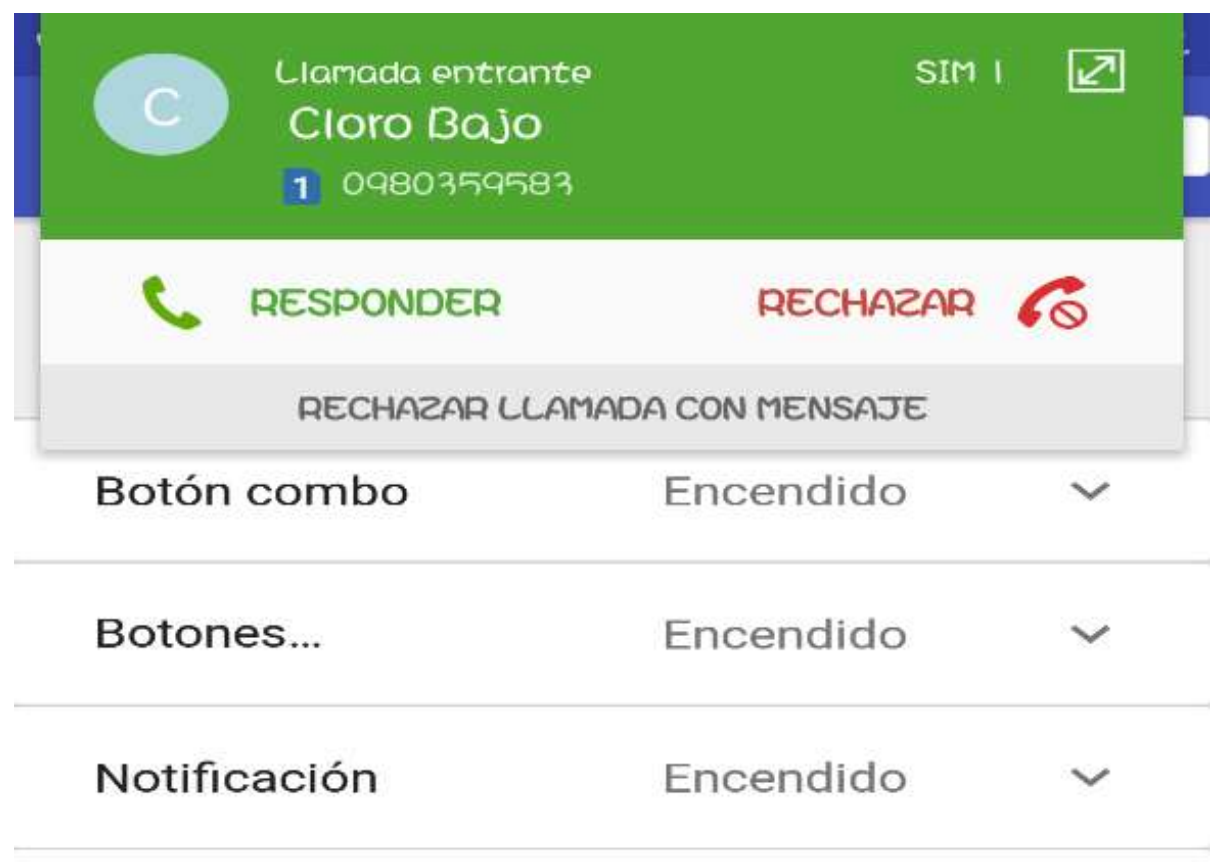

Figura 8. Alerta de llamada. Fuente. Pérez de Diego, 2015.

La conexión realizada se acopla dicha shield como se muestra en el siguiente diagrama, y también se adicionará librerías a la programación, la misma que fue sometida apruebas. 


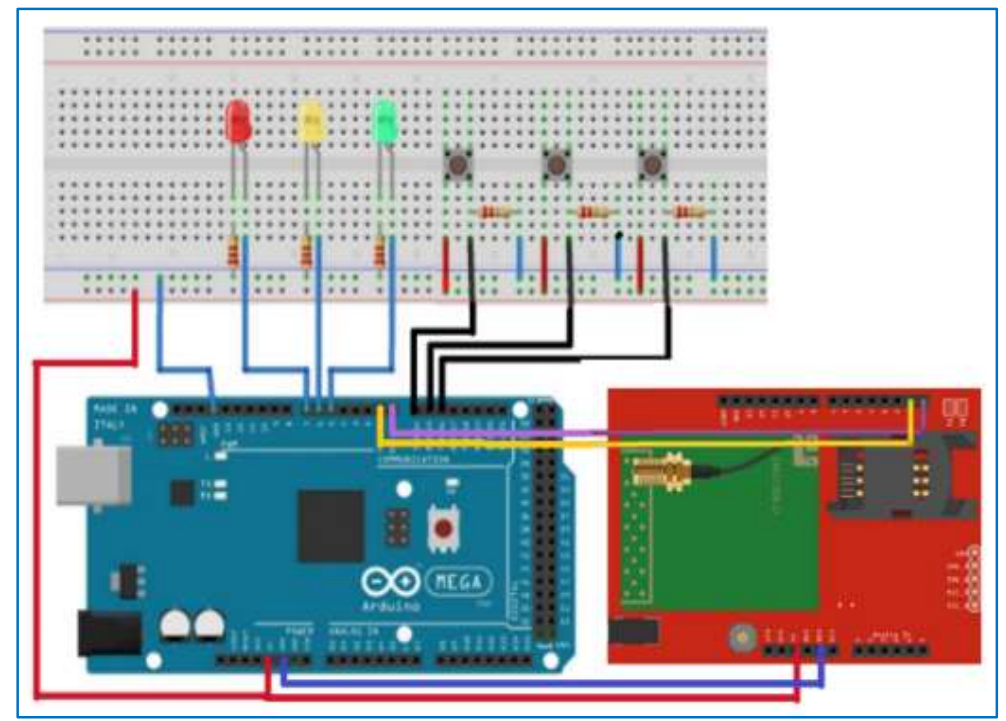

Figura 9. Diagrama eléctrico de sensores de nivel sim 900. Fuente. Pérez de Diego, 2015.

Con el sensor de control de oxigeno como se muestra en la Figura 10 se va a medir la calidad del aire que se encuentra en el ambiento del cuarto de máquinas o garita de clorado, además es por seguridad, ya que el cloro emite gases nocivos que pueden afectar a la salud del encargado de abastecer de pastillas y monitorear verificando los niveles permisibles para la persona encargada (Llamas, 2016).

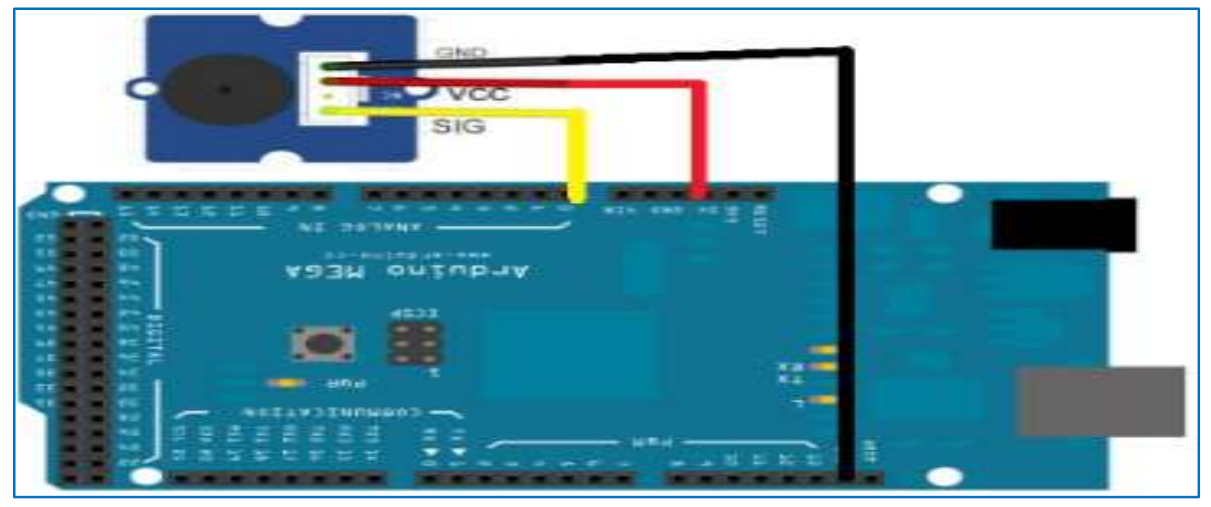

Figura 10. Diagrama de conexión del sensor de oxigeno. Llamas, 2016. 
El monitoreo del sistema se implementa por medio de dos dispositivos un emisor el cual envia datos recolectados de la garita de cloración y otro dispositio receptor que lee los datos para posteriormente visusalizar un una pantalla nextion, el envio de señal se realiza desde la garita de clorado el cual se encarga de leer los datos, procesarlos y enviarlos hacia una placa de recepción en el cual se monitoreara el funcionamiento del sistema sin la necesidad de dirigirse a la garita de clorado, para la conexión del dispositivo se toma en cuenta el siguiente diagrama.
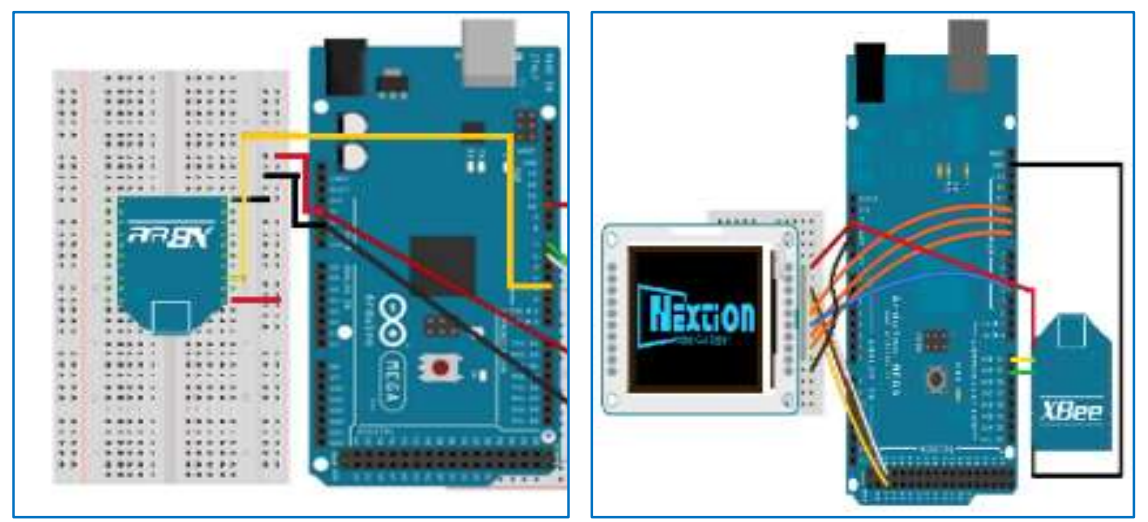

Figura 11. Diagrama eléctrico del dispositivo emisor y receptor. Fuente. Llamas, 2016).

\section{RESULTADOS}

Una vez hechas las pruebas de funcionamiento e identificados los dispositivos de emisión, recepción y alerta del sistema. Se procede a la instalación de la caja de control y caja de monitoreo como se

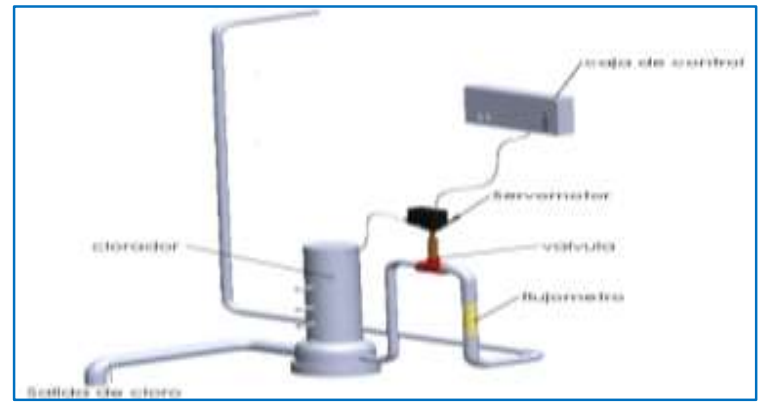

Figura 12. Sistema de dorado automatizado. Fuente. Llamas, 2016). 
El elemento emisor va a medir el volumen del agua que corre por la pastilla de cloro, procesa los datos obtenidos y ejecuta el cierre o apertura del servomotor, si las pastillas se encuentran por debajo del $10 \%$ se procesa los datos y ejecuta el encendido de luces indicadoras. Este sistema se conecta en paralelo para ejecutar la notificación de alerta en caso de una emergencia.

Realizadas las pruebas de conexión en vacío se procede al montaje de la caja de control donde se encuentra el elemento emisor como se puede observar en la figura 13.

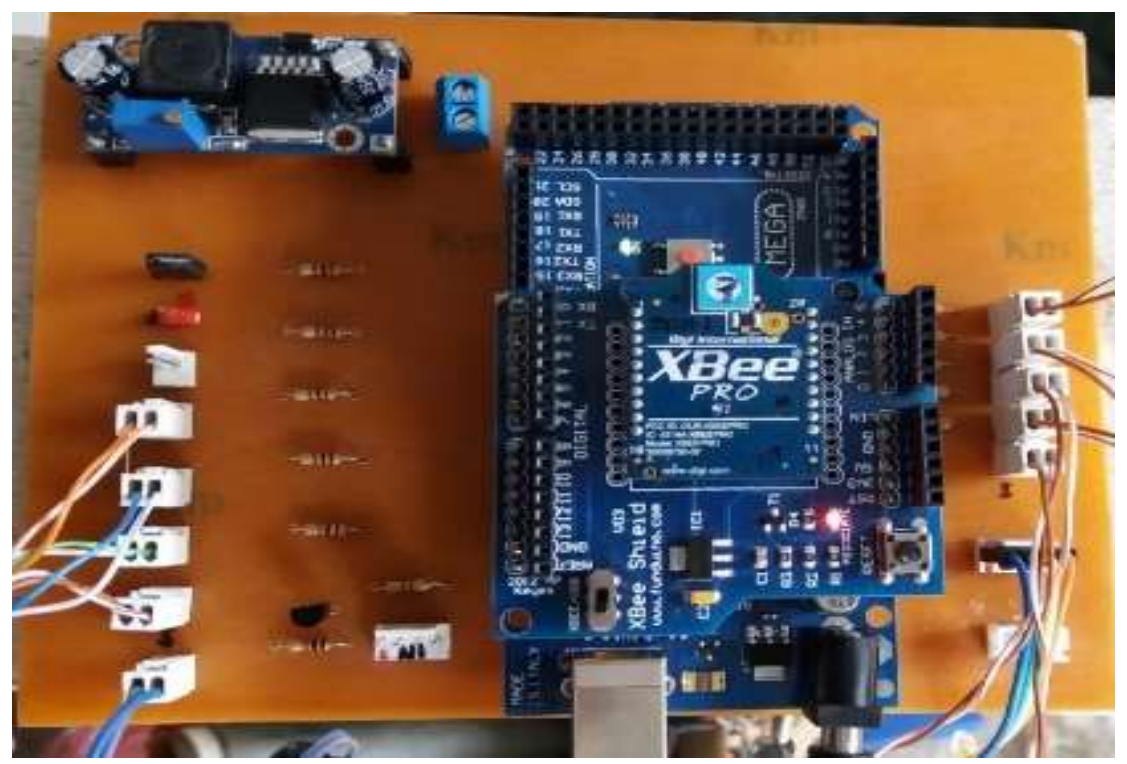

Figura 13. Montaje y acople de dispositivos electrónicos. Fuente. Llamas, 2016).

El elemento receptor procesara los datos y se visualizará en la pantalla el nivel de cloro, la distancia, los litros de agua y el nivel de oxigeno del ambiente considerando normal y peligroso como se ve en la Figura 14, también se encenderá luces indicadoras según el porcentaje de pastillas de cloro. 
Revista Arbitrada Interdisciplinaria KOINONIA

Año V. Vol V. N 9 . Enero - Junio 2020

Hecho el depósito de Ley: FA2016000010

ISSN: 2542-3088

FUNDACIÓN KOINONIA (F.K). Santa Ana de Coro. Venezuela.

Jhonny Marcelo Orozco-Ramos; Juan Carlos Cayán-Martínez; Eduardo Francisco García-Cabezas; Gabriel Pilataxi-Contreras

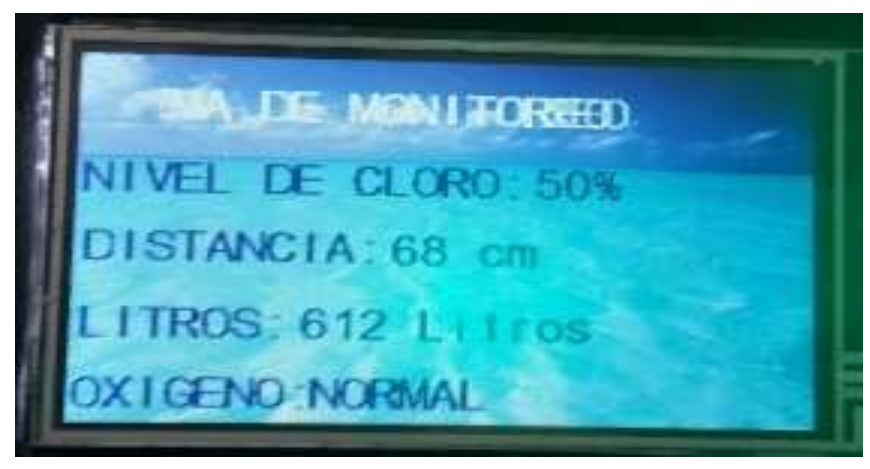

Figura 14. IMA de monitoreo. Fuente. Llamas, 2016).

Para la calibración del sistema se realiza las mediciones necesarias para llegar a los niveles óptimos para el consumo humano en los siguientes puntos:

1. Tanque de almacenamiento

2. Tanque de distribución

3. Punto de consumo alto

4. Punto de consumo medio

5. Punto de consumo bajo.

La toma de las muestras se realiza en horas de la tarde y pasando 1 día después de su modificación de la dosificación debido a que en 24 horas el líquido vital fluye por todo el sistema permitiendo tener muestras exactas como se ve en la Figura 15, el cloro lleva solo 30 min para garantizar una desinfección satisfactoria. 


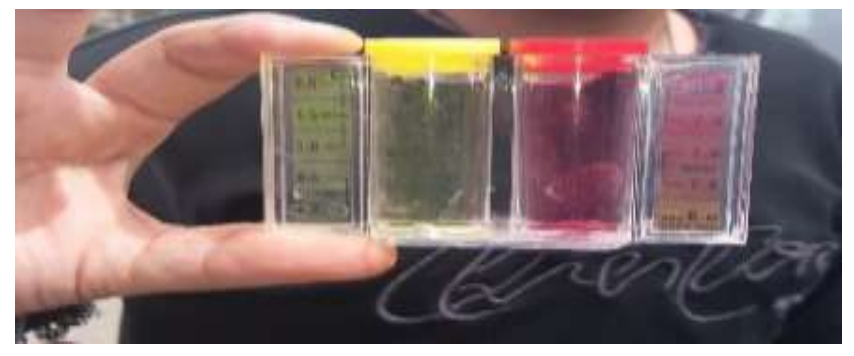

Figura 15. Toma de muestras para medición de cloro. Fuente. Autores.

\begin{tabular}{|l|l|l|l|l|l|}
\hline No $^{\circ}$ muestra & $\begin{array}{l}\text { Tanque de } \\
\text { almacenamiento }\end{array}$ & $\begin{array}{l}\text { Tanque de } \\
\text { distribución }\end{array}$ & $\begin{array}{l}\text { Punto de } \\
\text { consumo más } \\
\text { cercano }\end{array}$ & $\begin{array}{l}\text { Punto de } \\
\text { consumo } \\
\text { intermedio }\end{array}$ & $\begin{array}{l}\text { Punto de } \\
\text { consumo más } \\
\text { lejano. }\end{array}$ \\
\hline 1 & 0,99 & 0,72 & 0,73 & 0,61 & 0,11 \\
\hline 2 & 1,1 & 0,7 & 0,74 & 0,7 & 0,33 \\
\hline 3 & 1,0 & 0,8 & 0,8 & 0,55 & 0,2 \\
\hline 4 & 0,98 & 0,9 & 0,7 & 0,5 & 0,3 \\
\hline CESTTA & 1,1 & 0,8 & \multicolumn{3}{|c|}{0,1} \\
\hline
\end{tabular}

Figura 16. Recolección de tomas de muestras. Fuente. Autores.

Con los datos obtenidos por el laboratorio de agua de la ESPOCH - CESTAP se calibra según las muestras obtenidas para aumentar o disminuir la dosificación y poder mantener en los puntos de consumo un nivel óptimo como lo establece la norma INEN 1108. La última muestra se realiza con la ayuda de un photometro dicho instrumento también es un medidor de concentración de cloro, para la utilización el mismo se realizó gestión en la Empresa Municipal de Agua Potable y Alcantarillado de Ambato (EP- EMAPA-A) porque las mediciones o adquisición del equipo es muy costoso, para la utilización de dicho instrumento debe realizarlo un técnico con conocimientos en la materia, y cabe recalcar que se realizó la gestión para tomar muestras más exactas y verídicas porque el sistema está diseñado para el consumo humano. 
En la última muestra indica los rangos de concentración de cloro que va de 0,3 a $1 \mathrm{ml} / \mathrm{l}$ según la ubicación de las casas considerando las más cercanas con un elevado porcentaje de cloro sin descuidar los parámetros accesibles para el consumo humano como se muestra en la Figura 17, aumentando la fiabilidad de la muestra por medio de nuevos análisis de cloro residual libre en CESTTA.

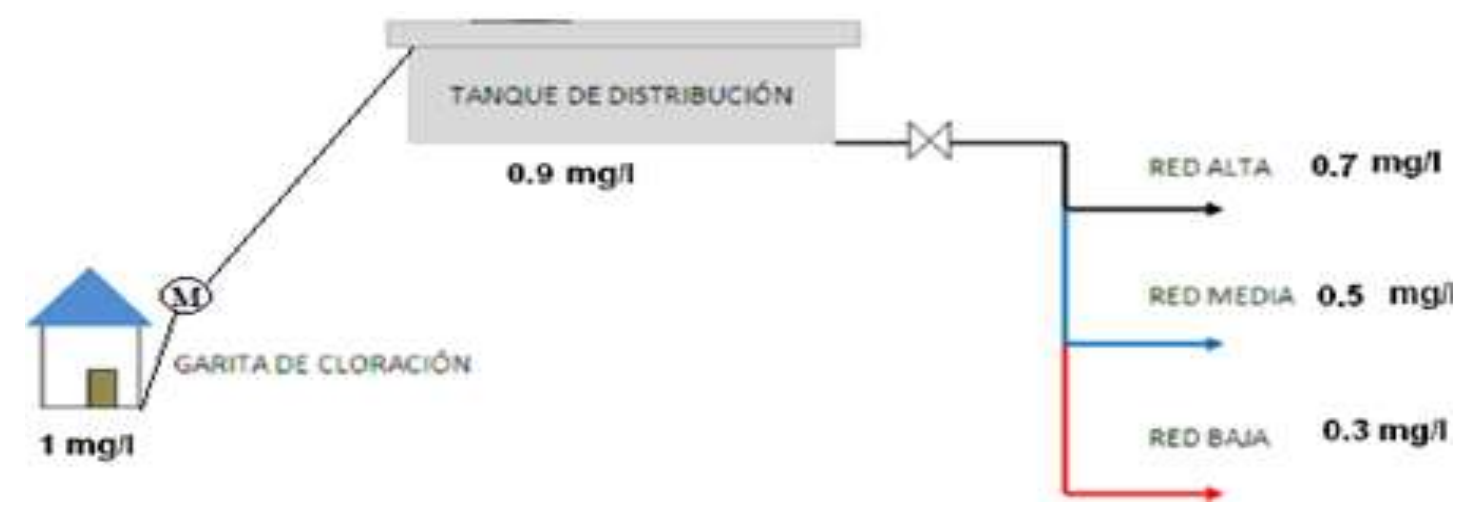

Figura 17. Resultados en los puntos de muestreo. Fuente. Autores.

Las pruebas de análisis microbiológicos en el sistema de agua potable del caserío muestra en un estado incicial con un contenido de coliformes fecales y totales en donde se evidencio que existía microorganismos y bacterias, por cuanto no existía ningún tratamiento de agua, las demás pruebas se realizaron para calibrar el sistema de clorado hasta llegar a la calibración con un porcentaje final de condiciones óptimas de cloro de $1 \mathrm{ml} / \mathrm{l}$ eliminando microorganismos y bacterias, todas las pruebas fueron realizadas en el laboratorio del CESTTA, además se realizaron pruebas de cloro residual libre rigiéndose a los límites permisibles según la norma INEN 1108 de agua para consumo.

\section{CONCLUSIONES}

El sistema automatizado de clorado fue diseñado bajo la referencia de la norma INEN 1108, por cuanto el sistema se implementó para el consumo humano, el sistema se 
encuentra totalmente automatizado, solo debe intervenir el ser humano para el monitoreo el cual se diseñó para que se realice de forma inalámbrica.

El sistema de cloración automatizado evita que los trabajadores pasen tiempo en el sitio verificando los niveles de cloro admisibles para el consumo humano por medio de llamadas y niveles de cloro por medio de la pastilla falsa, además salvaguarda la integridad de las personas al enviar las condiciones del ambiente evitando inhalación de esta sustancia y las afecciones.

Se realizó el diseño de un sistema de clorado automatizado de fácil utilización y monitoreo con la selección adecuada de elementos de bajo costo y gran fiabilidad para su correcta funcionalidad.

El sistema utilizado por medio de open source (software libre) permite replicar esta tecnología en muchos procesos industriales y de control en el monitoreo de sistemas de aguas.

Al ser un sistema desarrollado para el consumo humano se realizó pruebas de funcionabilidad de todos los elementos, sometiéndolo a pruebas de campo antes de su instalación final, para asegurar su correcto funcionamiento se montó los elementos en placas de baquelita fenólica. Una vez cubiertas las pruebas de campo se procedió a su instalación final.

Las calibraciones del sistema se procedieron a la toma de muestras de concentración de cloro las cuales se calibro acorde a la norma INEN 1108, valores de $1,1 \mathrm{mg} / \mathrm{l}$ en la casa de máquinas o garita de clorado, 0,8 mg/l en el tanque de distribución y de 0,7 a 0,3 mg/l en la red de distribución según los análisis que se realizaron en CESTTA

\section{AGRADECIMIENTOS}

Agradecemos al proyecto del agua potable del Caserío Mollepamba, cantón Ambato en la provincia Tungurahua por permitirnos realizar esta investigación, y a su vez a los estudiantes Gabriel Pilataxi Contreras y Jonathan Santos Zambrano por comenzar con la fase inicial del mismo. 


\section{REFERENCIAS CONSULTADAS}

Academia Nacional de Ciencias (2018). El agua potable apta para el consumo es esencial. [Safe drinking water is essential]. Recuperado de https://n9.cl/6al9

Briñez K,Guarnizo J, Arias S. (2012). Calidad del agua para consumo humano en el departamento del Tolima. [Quality of water for human consumption in the department of Tolima].Rev. Fac. Nac. Salud Pública; 30(2): 175-182. Recuperado de https://n9.cl/06rt

Cárdenas, D, \& Patiño, F. (2011). Sistema de Abastecimiento de Agua Potable. [Drinking Water Supply System]. Tesis de grado. Facultad de Ingeniería de la Universidad de Cuenca, Ecuador. Recuperado de https://n9.cl/gi71

Guillemes Peira, Á. (2015). Desarrollo de un sistema para la desinfección de agua de consumo mediante tratamiento electroquímico. [Development of a system for the disinfection of drinking water by electrochemical treatment]. Universidad, Ciencia y Tecnología, 19(75), 75-81. Recuperado de https://n9.cl/uzq0

HIDRITEC (2016). Sistemas de Cloración. [Chlorination Systems]. Recuperado de https://n9.cl/fv08

Instituto Ecuatoriano de Normalización (2011). NTE INEN 1108:2011. Cuarta revisión. [NTE INEN 1108: 2011. Fourth revision]. Recuperado de https://n9.cl/wvfd

Mercado Dávila, R., Márquez Rosano, C., Noriero Escalante, L., \& Cervantes Herrera, J. (2019). Sistemas normativos locales sobre los derechos de uso y acceso al agua. [Local regulatory systems on water use and access rights]. Revista Arbitrada Interdisciplinaria Koinonía, 4(8), 489-522. http://dx.doi.org/10.35381/r.k.v4i8.296

Llamas, L. (2016). Detector de gases con Arduino y la familia de sensores MQ. [Gas detector with Arduino and the $\mathrm{MQ}$ family of sensors]. Recuperado de https://n9.cl/pzcf

Molina, E, Quesada, F, Calle, A, Ortiz, J, \& Orellana, D. (2018). Consumo sustentable de agua en viviendas de la ciudad de Cuenca. [Sustainable water consumption in homes in the city of Cuenca]. Ingenius. Revista de Ciencia y Tecnología, (20), 2837. https://dx.doi.org/10.17163/ings.n20.2018.03

Pérez-Vidal, A., Díaz-Gómez, J., Salamanca-Rojas, K., \& Rojas Torres, L. (2016). Evaluación del tratamiento de agua para consumo humano mediante filtros Lifestraw ${ }^{\circledR}$ y Olla Cerámica. [Evaluation of water treatment for human consumption using Lifestraw® filters and Ceramic Pot]. Revista de Salud Pública, 18(2), 275289. https://doi.org/10.15446/rsap.v18n2.48712 
Revista Arbitrada Interdisciplinaria KOINONIA

Año V. Vol V. Nº 9 . Enero - Junio 2020

Hecho el depósito de Ley: FA2016000010

ISSN: 2542-3088

FUNDACIÓN KOINONIA (F.K). Santa Ana de Coro. Venezuela.

Jhonny Marcelo Orozco-Ramos; Juan Carlos Cayán-Martínez; Eduardo Francisco García-Cabezas; Gabriel Pilataxi-Contreras

Pérez de Diego, D. (2015). Sensores de distancia por ultrasonidos. [Ultrasonic distance sensors]. Recuperado de https://n9.cl/ak54l

Revista ARQHYS (2012). Sistema de agua potable. [Drinking water system]. Recuperado de https://n9.cl//8ki

(C2020 por los autores. Este artículo es de acceso abierto y distribuido según los términos y condiciones de la licencia Creative Commons Atribución-NoComercial-Compartirlgual 4.0 Internacional (CC BY-NC-SA 4.0)

(https://creativecommons.org/licenses/by-nc-sa/4.0/). 